\title{
Beer Consumption: Health Effects
}

\author{
Gurmeet Singh Sarla* \\ Senior Registrar, 159 General Hospital, India
}

*Corresponding author: Dr. Gurmeet Singh Sarla, Senior Registrar, 159 General Hospital, India

Received: 跙 September 27, 2019

Published: 跳 October 04, 2019

\begin{abstract}
Background: Beer is one of the most seasoned and most broadly expended alcoholic beverages on the planet and is the third most commonly consumed drink after water and tea world over.

Aim: The aim of this review article was to study the health effects of beer consumption and compare the positive effects of consumption of wine, beer and spirits when consumed in moderation.

Methods: Literature was searched in the form of epidemiological studies, prospective studies and clinical trials and the health effects of different alcoholic beverages were studied and compared when consumed in moderation. Moderate consumption of beer was defined as non bingeing utilization of 1 beverage for every day in ladies and upto 2 beverages for each day in men.

Conclusion: Although alcohol consumption is a two-sided coin, moderate alcohol consumption in the form of wine or beer has been shown to have a protective role for the cardiovascular system and in addition to being anti-carcinogenic. Both wine and beer consumption in moderation have been associated with health benefits, but to a lesser degree with beer as compared to that of wine , probably because of beer's lower phenolic content. Healthy effects of wine and beer are greater in combination with a healthy diet. The main protective effects on the cardiovascular system and cancer resulting from moderate wine and beer intake is mainly due to their common components, alcohol and polyphenols. The general recommendations are one drink $(150 \mathrm{~mL}$ of wine or $10 \mathrm{~g}$ of alcohol) daily for women and two drinks $(300 \mathrm{~mL}$ of wine or $20 \mathrm{~g}$ of alcohol) daily for men.
\end{abstract}

Keywords: Beer; Alcohol; Wine; Spirits; Moderate consumption; Xanthohumol

\section{Introduction}

Doctors ought to know about the developing proof supporting the dietary and medical advantages of moderate utilization of alcohol as a component of a sound way of life Beer is one of the most seasoned and most broadly expended alcoholic beverages on the planet and in America it adds to $55.3 \%$ of the liquor devoured. It is the third most commonly consumed drink after water and tea world over. Beer is fermented from oat grains-most usually from malted grain, however wheat, maize, and rice may likewise be utilized. Moderate, non-bingeing beer utilization as 1 beverage for every day in ladies and upto 2 beverages for each day in men, diminishes the danger of cardiovascular ailment. This impact is like that of wine, at similar alcohol amounts [1]. The strength of current brew is more often than not around $4 \%$ to $6 \%$ alcohol by volume (ABV), in spite of the fact that it might differ somewhere in the range of $0.5 \%$ and $20 \%$.

\section{A big No!}

Consumption of beer, at any measurement isn't prescribed for youngsters, teenagers, pregnant ladies, people in danger to create liquor abuse, those with cardiomyopathy, cardiovascular arrhythmias, depression, liver and pancreatic illnesses or anybody occupied with activities that require fixation, aptitude or coordination [1].

\section{Wine}

The off late affirmed willful mark on wine saying that" The proud people who made this wine encourage you to consult your family doctor about the health effects of wine consumption" suggests that doctors ought to advance wine as the favored wellspring of dietary alcohol. However, studies evaluating the relative benefits of wine versus beer versus spirits suggest that moderate consumption of any alcoholic beverage is associated with lower rates of cardiovascular disease. From a nutritional standpoint, beer contains more protein and vitamin B complex than wine [2]. The antioxidant content of beer is equivalent to that of wine, but the specific antioxidants are different because the barley and hops used in the production of beer contain flavonoids different from those in the grapes used in the production of wine [2]. Wine has a long history of use as a medicine making it the world's oldest documented human made 
medicine and is recommended as an antiseptic for treating wounds, a digestive aid, for lethargy, diarrhoea and as an analgesic for pain from childbirth [3]. The risk of colon cancer, prostatic cancer and breast cancer can be reduced by consuming moderate amounts of wine and has been proven to have positive health effects in patients with diabetes mellitus and cardiovascular diseases [3].

\section{Arterial Stiffness}

Increased arterial stiffness has been identified as an independent risk factor for future cardiovascular disease [4]. Epidemiological examinations uncover a J-shaped relationship between liquor utilization and blood vessel stiffness, with blood vessel hardening lower among mild-to-moderate consumers than overwhelming consumers or non-drinkers [5]. The changes in arterial stiffness are generally thought to results from structural changes (i.e., elastin and collagen content), functional changes (i.e., sympathetic nervous activity, vasoactive substances), or a combination of both [6]. Consumption of alcoholic beverages in excess of the mild-tomoderate level is known to elicit a reduction in arterial compliance, which means an increase in arterial stiffness [7].

\section{Pattern of drinking and type of alcoholic beverage}

Moderate drinkers have a lower risk of developing coronary heart disease and less mortality compared to both heavy drinkers and abstainers, heavy drinkers being the ones with the highest risk [8]. Mukamal et al. reported that alcohol intake distributed over the week inversely associates with the risk of myocardial infarction independently of the type of beverage or the proportion consumed with meals [9]. Some studies supported the benefits of wine on cardiovascular outcomes and mortality and depicted that a J-shaped relationship was found in wine, but neither in beer nor spirits [10]. A recent study reported by Costanzo et al. provided evidence that the J-shaped association is found in both wine and beer, but not in spirits [11]. Fermented beverages, both wine and beer are rich in antioxidants, mainly polyphenolic compounds [12], that are missing in spirit beverages.

\section{Mechanism of action}

A number of studies and clinical trials have suggested that alcoholic beverages may exert different protective effects against atherosclerosis development either by modulating lipid metabolism, platelet activity, inflammation, and thrombogenic factors [13]. Specific interest focuses on fermented alcoholic beverages such as wine or beer wherein epidemiological evidence and results from prospective clinical trials suggests that these beverages with heterogenous content of non-alcoholic components might confer better cardiovascular protection than spirits $[1,14]$.

\section{How much is too much!}

Epidemiological and clinical studies have pointed out that moderate consumption of beer viz one glass a day for females and two glasses a day for males, is associated with decreased incidence of cardiovascular disease (CVD), hypertension, diabetes, and certain types of cancer, including colon, basal cell, ovarian, and prostate carcinoma. Excessive intake has been associated with hypertension and atrial fibrillation [15].

\section{Content}

Beer is rich in nutrients such as carbohydrates, amino acids, minerals, vitamins and other compounds such as polyphenols. Hop (Humulus lupulus L.) is one of the raw materials of beer which serves as an important source of phenolic compounds. Dried hop cones contain about $14.4 \%$ of polyphenols, mainly phenolic acids, prenylated chalcones, flavonoids, catechins and pro- antocianidins [16]. Around $30 \%$ of polyphenols from beer comes from hops and $70 \%-80 \%$ originates from malt [17].

\section{Given a choice!}

A recent meta-analysis including a parallel and separate evaluation of wine and beer consumption indicated a similar protective effect for beer and wine against cardiovascular risk [18]. On the contrary, no statistically significant association with vascular events was apparent for the intake of spirits- the type of alcoholic drink with the highest alcohol concentration and the lowest polyphenolic concentration- suggesting that the polyphenolic constituents found in wine or beer could be responsible for the beneficial effect of alcoholic beverages on vascular events [19]. Results of another study reveals that moderate consumption of alcoholic drinks with a high alcoholic grade (liquors and distillates) also has a cardio-protector effect [20] explaining the fact that part of the beneficial effects of alcoholic beverages is largely due to ethanol, and not to the other specific components of each type of drink.

\section{Anti- cancer role}

Xanthohumol is the best studied anti-carcinogenic present in beer which acts by inhibiting the metabolic activation of procarcinogens, detoxifying enzyme inducers of carcinogens [21]. Other compounds in beer with anti-carcinogenic capacity are 8-prenilnaringenin, isoxanthohumol and other prenilflavonoids, as well as the flavanones, humulones and proantocianidins [22].

\section{Conclusion}

Although heavy and excessive beer consumption exerts deleterious effects on the human body, with increased disease risks on many organs and is associated to significant social problems such as addiction, accidents, violence and crime, literature shows no harm with moderate beer consumption for major chronic conditions and some benefit against cardiovascular disease [1]. The main protective effects on the cardiovascular system and cancer resulting from moderate wine and beer intake is mainly due to their common components, alcohol and polyphenols.

It must be emphasized that the benefits associated with wine and beer are dependent upon moderate consumption. The general recommendations are one drink ( $150 \mathrm{~mL}$ of wine or $10 \mathrm{~g}$ of alcohol) daily for women and two drinks (300mL of wine or $20 \mathrm{~g}$ of alcohol) daily for men. These different recommended daily doses of alcohol between genders are explained by the fact that women are more sensitive to the effects of alcohol on the body.

Healthy effects of wine and beer are greater in combination with a healthy diet. The health benefits associated with the 
Mediterranean diet, which combines moderate wine and beer consumption with a diet rich in fruits, vegetables and whole grains, suggests that polyphenols have synergistic effects with compounds found in other groups of foods.

There is no evidence to support endorsement of one type of alcoholic beverage over another [2]. However some studies have revealed that although both wine and beer consumption in moderation have been associated with health benefits, but to a lesser degree with beer as compared to that of wine, probably because of beer's lower phenolic content.

Although alcohol consumption is a two-sided coin, moderate alcohol consumption in the form of wine or beer has been shown to have a protective role for the cardiovascular system and in addition to being anti-carcinogenic. American Heart Association recommends that heavy drinkers or alcohol abstainers should not be encouraged to drink wine for health reasons.

\section{References}

1. De Gaetano G, Costanzo S, Di Castelnuovo A, Badimon L, Bejko D, et al (2016) Effects of moderate beer consumption on health and disease: A consensus document. Nutr Metab Cardiovasc Dis 26(6): 443-467.

2. Denke MA (2000) Nutritional and health benefits of beer. Am J Med Sci 320(5): 320-326.

3. Gurmeet Singh Sarla (2019) Wine: An Alcoholic Beverage or a Wonder Drink. Journal of Medical Surgical Nursing Practice and Research 1(2): 33-38.

4. Laurent S, Boutouyrie P (2007) Recent advances in arterial stiffness and wave reflection in human hypertension. Hypertension 49: 1202-1206.

5. Mattace Raso FU, van der Cammen TJ, van den Elzen AP, Schalekamp MA, Asmar R, et al. (2005) Moderate alcohol consumption is associated with reduced arterial stiffness in older adults: the Rotterdam study. J Gerontol A Biol Sci Med Sci 60: 1479-1483.

6. Tanaka H, Safar M. E (2005) Influence of lifestyle modification on arterial stiffness and wave reflections. Am J Hypertens 18: 137-144.

7. Fantin F, Bulpitt CJ, Zamboni M, Cheek E, Rajkumar C (2016) Arterial compliance may be reduced by ingestion of red wine. J Hum Hypertens 30: 68-72.

8. Costanzo S, Di Castelnuovo A, Donati MB, Iacoviello L, De Gaetano G (2010) Alcohol Consumption and Mortality in Patients with Cardiovascular Disease. A Meta-Analysis. J Am Coll Cardiol 55: 13391347.
9. Mukamal KJ, Conigrave KM, Mittleman MA, Camargo CA, Stampfer MJ, et al. (2003) Roles of drinking pattern and type of alcohol consumed in coronary heart disease in men. N Engl J Med 348: 109-118.

10. Gronbaek M, Becker U, Johansen D, Gottschau A, Schnohr P, et al. (2000) Type of alcohol consumed and mortality from all causes, coronary heart disease, and cancer. Ann Intern Med 133: 411-419.

11. Costanzo S, Di Castelnuovo A, Donati MB, Iacoviello L, De Gaetano G (2011) Wine, beer or spirit drinking in relation to fatal and non-fatal cardiovascular events: A meta-analysis. Eur J Epidemiol 26: 833-850.

12. Arranz S, Chiva Blanch G, Valderas Martínez P, Medina Remón A, Lamuela Raventós RM, et al. (2012) Wine, beer, alcohol and polyphenols on cardiovascular disease and cancer. Nutrients 4: 759-781.

13. Vilahur G, Casani L, Guerra JM, Badimon L (2012) Intake of fermented beverages protect against acute myocardial injury: Target organ cardiac effects and vasculoprotective effects. Basic Res Cardiol 107.

14. Chiva Blanch G, Magraner E, Condines X, Valderas Martínez P, Roth I, et al. (2015) Effects of alcohol and polyphenols from beer on atherosclerotic biomarkers in high cardiovascular risk men: A randomized feeding trial. Nutr Metab Cardiovasc Dis 25: 36-45.

15. OKeefe JH, Bhatti SK, Bajwa A, DiNicolantonio JJ, Lavie CJ (2014) Alcohol and cardiovascular health: The dose makes the poison or the remedy. Mayo Clin Proc 89: 382-393.

16. Taylor AW, Barofsky E, Kennedy JA, Deinzer ML (2003) Hop (Humulus lupulus L.) proanthocyanidins characterized by mass spectrometry, acid catalysis, and gel permeation chromatography. J Agric Food Chem 51: 4101-4110.

17. De Keukeleire D, De Cooman L, Rong H, Heyerick A, Kalita J, et al. (1999) Functional properties of hop polyphenols. Basic Life Sci 66: 739-760.

18. Costanzo S, Di Castelnuovo A, Donati MB, Iacoviello L, De Gaetano G (2011) Wine, beer or spirit drinking in relation to fatal and non-fatal cardiovascular events: A meta analysis. Eur J Epidemiol 26: 833-850.

19. Di Castelnuovo A, Costanzo S, Di Giuseppe R, De Gaetano G, Iacoviello L (2009) Alcohol consumption and cardiovascular risk: Mechanisms of action and epidemiologic perspectives. Future Cardiol 5: 467-477.

20. van der Gaag MS, van Tol A, Scheek LM, James RW, Urgert R, et al. (1999) Daily moderate alcohol consumption increases serum paraoxonase activity; a diet-controlled, randomised intervention study in middleaged men. Atherosclerosis 147: 405-410.

21. Gerhauser C, Alt A, Heiss E, Gamal Eldeen A, Klimo K, et al. (2002) Cancer chemopreventive activity of xanthohumol, a natural product derived from hop. Mol Cancer Ther 1: 959-969.

22. Chung WG, Miranda CL, Stevens JF, Maier CS (2009) Hop Proanthocyanidins induce apoptosis, protein carbonylation, and cytoskeleton disorganization in human colorectal adenocarcinoma cells via reactive oxygen species. Food Chem Toxicol 47: 827-836.

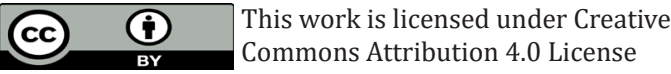

To Submit Your Article Click Here:

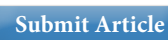

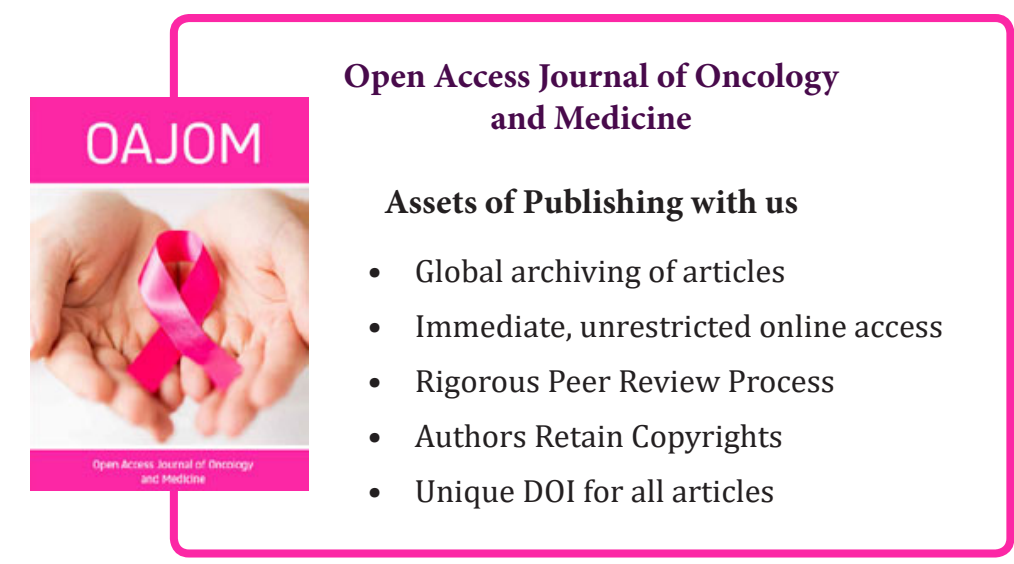

DOI: $10.32474 /$ OAJOM.2019.03.000159

Assets of Publishing with us

Global archiving of articles

- Immediate, unrestricted online access

- Rigorous Peer Review Process

- Authors Retain Copyrights

- Unique DOI for all articles 